\title{
Fonoaudiologia, conflitos decisórios e pacientes disfágicos: revisão integrativa
}

Márcio José da Silva Moreira ${ }^{1}$, Roberta Nascimento de Oliveira Lemos dos Santos ${ }^{2}$, Marisa Palacios ${ }^{3}$

1. Universidade Federal Fluminense (UFF), Nova Friburgo/RJ, Brasil. 2. Instituto Federal do Rio de Janeiro, Rio de Janeiro/RJ, Brasil. 3. Universidade Federal do Rio de Janeiro (UFRJ), Rio de Janeiro/RJ, Brasil.

\section{Resumo}

A disfagia tem impactos negativos multidimensionais na vida do paciente disfágico e pode gerar conflitos decisórios relacionados à alimentação. $O$ objetivo deste artigo é revisar a literatura sobre fonoaudiologia, conflitos na tomada de decisão e agentes envolvidos nas deliberações sobre a nutrição desse tipo de paciente. Trata-se de estudo exploratório-descritivo, de revisão integrativa, com análise de conteúdo conforme proposta por Bardin. As bases de dados utilizadas foram: PubMed, Scopus, Web of Science, Cochrane, Embase e Biblioteca Virtual em Saúde. Identificaram-se conflitos envolvendo o fonoaudiólogo, o paciente, a família e a equipe multidisciplinar. Nos artigos selecionados não foi possível identificar uma teoria ou método que fundamentasse a mediação desses conflitos. Não foram encontradas publicações brasileiras que respondessem à pergunta norteadora da revisão.

Palavras-chave: Transtornos de deglutição. Bioética. Fonoaudiologia.

\section{Resumen}

Fonoaudiología, conflictos de decisión y disfagia: revisión integradora

La disfagia tiene impactos negativos multidimensionales en la vida del paciente disfágico y puede generar conflictos de decisión relacionados con su alimentación. El objetivo de este artículo fue revisar la literatura sobre fonoaudiología, los conflictos de decisión y los agentes involucrados en el proceso de toma de decisiones para las deliberaciones relacionadas con la nutrición de este tipo de pacientes. Se trata de un estudio exploratorio y descriptivo, donde se realizó una revisión integradora con análisis de contenido y categorización por Bardin. Las bases de datos utilizadas fueron: PubMed, Scopus, Web of Science, Cochrane, Embase y Biblioteca Virtual en Salud. Se identificaron los conflictos entre fonoaudiólogo, paciente, familia y equipo multidisciplinario. En los artículos seleccionados no se identificó ninguna teoría o método que sustente la mediación de estos conflictos. No hay publicaciones nacionales que respondan a la pregunta orientadora.

Palabras clave: Trastornos de deglución. Bioética. Fonoaudiología.

\section{Abstract}

\section{Speech therapy, decision conflicts and dysphagic patients: an integrative review}

Dysphagia presents multidimensional negative impacts on the life of dysphagic patients and may generate decision conflicts related to their diet. This is a review of the literature on speech-language therapy, decision conflicts and the agents involved in the decision making process for deliberations related to the nutrition of this type of patient. This is an exploratory and descriptive study, with content analysis as proposed by Bardin. The databases used were PubMed, Scopus, Web of Science, Cochrane, Embase and Virtual Health Library. Conflicts involving the speech-language therapist, the patient, the family and the multidisciplinary team were identified. In the selected articles, no theory or method was identified to support the mediation of these conflicts. No Brazilian publications that answered the guiding question were found.

Keywords: Deglutition disorders. Bioethics. Speech, language and hearing sciences. 
A bioética se relaciona com outros saberes, e por isso é necessário entender conteúdos multidisciplinares para tratar de modo mais assertivo as questões bioéticas. O profissional de saúde pode ter dificuldades para analisar o cenário e identificar problemas que necessitam de uma análise moral e resolução célere. Essa análise deve levar em consideração aspectos éticos, morais, religiosos, jurídicos, científicos e técnicos ${ }^{1}$.

Pessini e Barchifontaine ${ }^{2}$ definem a bioética como um domínio de percepção plural, que emerge de demandas relacionadas ao aparecimento e uso de tecnologias aplicadas às ciências médicas. O campo de estudo abrange discussões sobre o cuidado e as relações nele instituídas. Seu objetivo é resguardar a integridade do paciente e promover boas práticas clínicas por parte dos profissionais de saúde, incluindo o fonoaudiólogo.

A fonoaudiologia se ocupa de questões relacionadas à comunicação humana, dando suporte teórico ao fonoaudiólogo para identificar, avaliar e reabilitar indivíduos que apresentem alterações na comunicação oral e escrita, na voz e na audição ${ }^{3}$. Com o passar dos anos, a fonoaudiologia tem expandido sua linha de atuação, englobando novos cenários terapêuticos e abordagens ${ }^{4}$. Um dos objetos das especialidades que surgiram dentro da profissão é a disfagia. O fonoaudiólogo especialista nessa área está capacitado para atuar na prevenção, avaliação e tratamento de alterações da deglutição em todos os ciclos de vida, priorizando o bem-estar do paciente, minimizando riscos e maximizando benefícios relacionados à saúde. A suspensão, indicação de via alternativa de alimentação ou liberação de nutrição por via oral ficam condicionadas à avaliação do fonoaudiólogo, em debate com a equipe multidisciplinar ${ }^{5}$.

Dividida em quatro fases (preparatória oral, oral, faríngea e esofágica), a deglutição é uma função do sistema estomatognático executada por estruturas que participam de outras funções, como fala, voz, respiração, mastigação e sucção. Qualquer alteração no trajeto do alimento da boca até o estômago é chamada de disfagia, e sua etiologia pode compreender doenças neuromusculares, tumorais, infecciosas, metabólicas e degenerativas ou eventos iatrogênicos ${ }^{6}$. A disfagia é caracterizada pela presença de penetração, aspiração e broncoaspiração do bolo alimentar, bem como de fluido oral, gástrico ou líquido, levando, em muitas situações, ao adoecimento do indivíduo. Observam-se impactos biopsicossociais mais intensos para o paciente disfágico em situação de vulnerabilidade, por causa do avanço da doença e da impossibilidade de cura, com prejuízos ao bem-estar e à qualidade de vida. A alimentação deve priorizar a manutenção do estado nutricional e hídrico de forma segura e eficaz, sem colocar em risco a saúde pulmonar do paciente ${ }^{7}$.

O presente artigo traz resultados de uma revisão integrativa com análise de conteúdo fundamentada em Bardin ${ }^{8}$. Toda a pesquisa se baseou na questão norteadora: "Quais são os principais atores da tomada de decisão envolvendo paciente disfágico e quais são os conflitos enfrentados por eles?".

\section{Método}

\section{Processo de revisão integrativa}

O estudo teve foco exploratório-descritivo e utilizou o método de revisão integrativa, o que viabilizou a síntese de dados já publicados e a identificação de práticas baseadas em evidências ${ }^{9,10}$. Quando o pesquisador lança um olhar qualitativo para a revisão sistemática, torna-se possível uma avaliação mais global, que inclua aspectos socioculturais, emocionais e comportamentais que fazem parte do cuidado em saúde. Seguindo essa linha, o pesquisador pode obter informações que lhe permitam sugerir caminhos e propor novas ferramentas teóricas ${ }^{11}$.

De acordo com Souza, Silva e Carvalho ${ }^{12}$, a revisão integrativa é caracterizada por seis fases bem delimitadas e de fácil organização e entendimento. Essas fases consistem em: 1) formular uma questão norteadora; 2) estabelecer critérios de inclusão e exclusão para integrar apenas documentos que realmente respondam a essa questão; 3 ) determinar quais informações vão compor o corpus da revisão integrativa; 4) interpretar os dados extraídos; 5) apresentar os resultados obtidos; e 6) sintetizar o conhecimento sobre a temática definida no início da revisão. Na presente revisão integrativa, incluímos nesse percurso mais uma fase: a análise de conteúdo, conforme proposta por Bardin ${ }^{8}$.

\section{Estratégias para identificar e selecionar estudos}

A pesquisa de literatura incluiu artigos em português, inglês ou espanhol publicados até 
29 de fevereiro de 2020. Não foi aplicado o filtro de data. O filtro de idiomas contemplou somente artigos em português, inglês e espanhol. Os artigos foram consultados na Plataforma Periódicos da Coordenação de Aperfeiçoamento de Pessoal de Nível Superior (Capes) por acesso remoto da Universidade Federal Fluminense e pela Universidade Federal do Rio de Janeiro.

As palavras-chave selecionadas constam dos vocabulários controlados Descritores em Ciências da Saúde (DeCS) e Medical Subject Headings (MeSH): "speech therapy", "bioethics", "ethics" e "decision making". A busca incluiu também sinônimos e termos relacionados, formando as seguintes chaves de busca: fonoaudiologia e alterações da deglutição (speech therapy or speech therapy or speech therapy approach or deglutition disorders or dysphagia rehabilitation); bioética e ética (bioethics or ethics or ethics of health care or biomedical ethics or bioethical hospital or medical ethics or ethicists or bioethicists or bioethical specialist* or ethics specialist ${ }^{*}$ or health care ethics or biomedical ethics or ethics, clinical or clinical ethics or hospital ethics or ethical aspects or ethics or ethics) e tomada de decisão compartilhada (decision making or decision making* shared or making* shared decision or decision making or shared decision making* or clinical decision-making or clinical decision making or decision-making clinical or medical decision-making or decision-making medical or medical decision making). As chaves de busca compostas pelas palavras bioética e ética foram unificadas por apresentarem termos em comum.

As chaves de busca foram combinadas para refinar os resultados. A pesquisa incluiu seis bancos de dados: PubMed (4 artigos), Scopus (32 artigos), Biblioteca Virtual em Saúde (BVS) (6 artigos), Embase (13 artigos), Cochrane (1 artigo) e
Web of Science (17 artigos). Esses indexadores foram escolhidos por terem apresentado mais artigos em busca prévia sem cruzamento das chaves. Consultou-se o site OpenGrey em busca de literatura cinzenta, mas a base não retornou nenhum dado relevante. Por fim, os resultados foram importados para o software gerenciador de referências Mendeley, que removeu duplicatas.

A inclusão dos estudos considerou a questão norteadora da pesquisa: "Quais são os principais atores da tomada de decisão envolvendo paciente disfágico e quais são os conflitos enfrentados por eles?". Foram excluídos artigos duplicados, artigos de revisão, cartas ao editor, artigos que tratavam exclusivamente da tomada de decisões do paciente, sem mencionar a equipe multidisciplinar ou o fonoaudiólogo, e estudos feitos em animais.

\section{Seleção dos artigos nas bases de dados}

A primeira seleção foi feita com base na leitura de títulos e resumos. Nessa etapa, dois revisores eliminaram os artigos que não atendiam aos critérios de inclusão. Para avaliar a concordância entre os revisores, $10 \%$ das publicações foram comparadas aleatoriamente. A leitura dos textos na íntegra foi necessária quando o título e o resumo não esclareciam se o estudo era pertinente para a questão norteadora.

Num segundo momento, os revisores leram na íntegra os artigos pré-selecionados, aplicando novamente os critérios de inclusão e exclusão. Houve acordo entre os dois revisores, portanto não foi necessário um terceiro revisor. Após a seleção, realizou-se uma busca manual de referências dos artigos incluídos na pesquisa. A representação do processo pode ser vista no flowchart da Figura 1, adaptado de revisão sistemática e metanálise ${ }^{13}$. 
Figura 1. Flowchart adaptado para seleção dos artigos da revisão integrativa

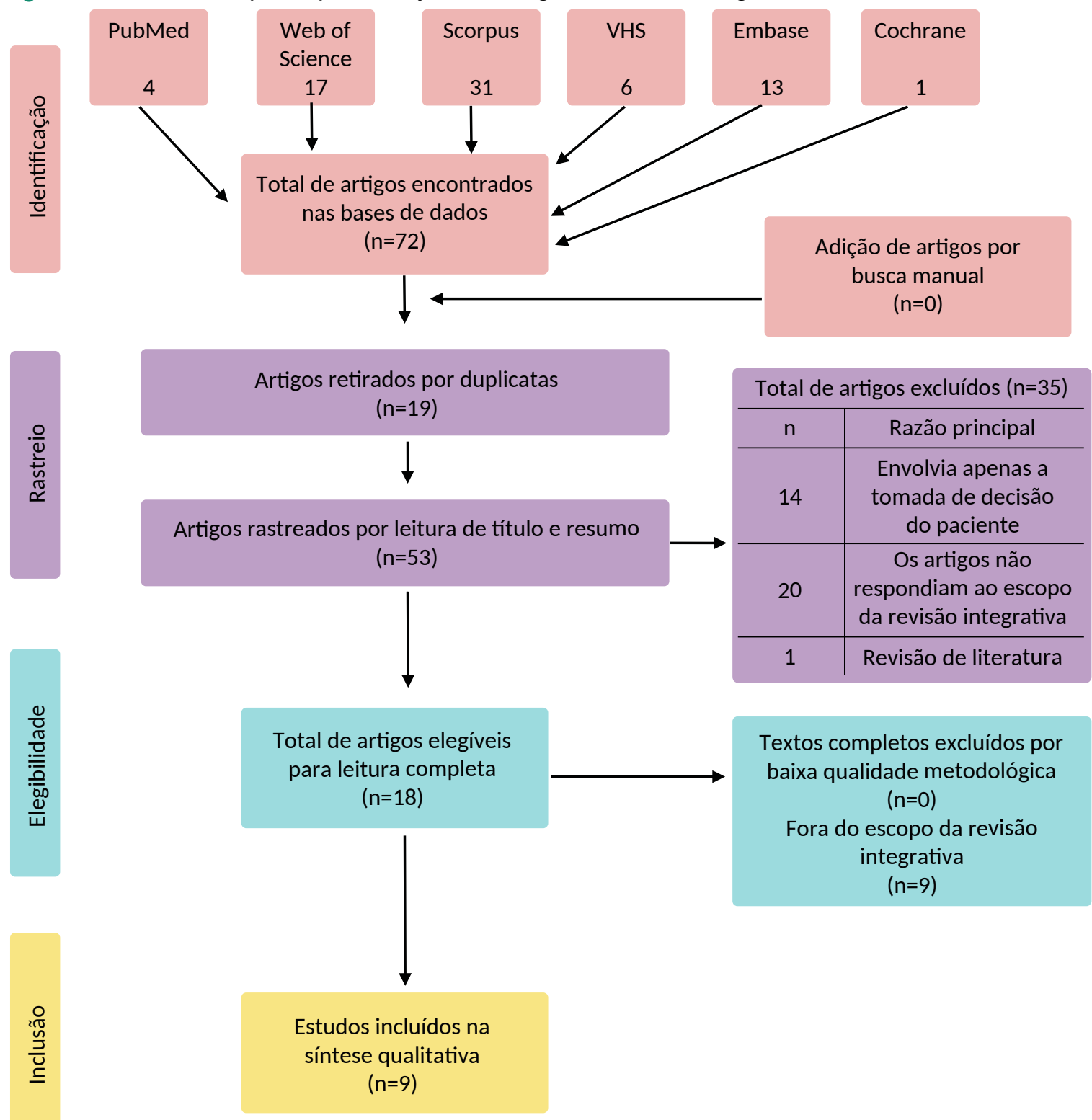

Fonte: Moher e colaboradores; $2009^{13}$.

\section{Avaliação de viés e risco metodológico}

Para avaliar o risco de viés, utilizou-se o instrumento JBI Critical Appraisal Checklist for Qualitative Research, desenvolvido pelo Joanna Briggs Institute ${ }^{11}$. Os itens contemplados por esse protocolo são: 1) "houve concordância entre o escopo filosófico e a metodologia descrita no artigo?"; 2) "houve concordância entre a metodologia empregada na pesquisa e a questão ou objetivos da pesquisa?"; 3) "houve concordância entre a metodologia empregada na pesquisa e os métodos de coleta de dados?"; 4) "houve concordância entre a metodologia empregada na pesquisa e a representação e análise de dados?"; 5) "houve concordância entre a metodologia empregada na pesquisa e a interpretação dos resultados?"; 6) "o pesquisador deixou claras as suas crenças e convicções relacionadas ao tema pesquisado?"; 7) "a influência do pesquisador na construção da pesquisa foi relatada no artigo?"; 
8) "os participante foram devidamente representados no relatório de pesquisa?"; 9) "houve aprovação ética?"; e 10) "as conclusões se relacionam com a análise ou interpretação dos dados?".

Para cada item foram admitidas quatro opções: "sim", "não", "não fica claro" e "não aplicável". No item "avaliação geral", as opções foram: "incluir o artigo na revisão integrativa", "excluir o artigo da revisão integrativa" ou "procurar mais informações" ${ }^{14}$. Os 9 artigos selecionados foram considerados elegíveis para compor a revisão integrativa, não havendo, portanto, nenhuma exclusão nessa etapa. Novamente, dois revisores aplicaram o checklist, e não houve discordância entre eles. Também não foi preciso entrar em contato com autores para complementar dados para a análise.

\section{Tratamento dos dados coletados}

Procedeu-se a uma avaliação qualitativa das publicações em busca de semelhanças ou diferenças, padrões e tendências gerais no modo como os estudos abordam o tema pesquisado. Os itens contemplados na coleta de dados foram: "ano", "autor", "título", "objetivos", "palavras-chave", "embates bioéticos" e "conclusões" (Quadro 1).

Considerando as características da revisão, adotou-se a técnica de análise de conteúdo, que utiliza a categorização temática. A aplicação dessa técnica começou pela pré-análise - etapa de planejamento, organização e leitura flutuante de todo o material reunido. Em um segundo momento, os artigos selecionados foram codificados com ajuda do programa computacional ATLAS.ti para Mac, onde foi gerado um relatório com a contagem e a identificação dos códigos (subcategorias). Com base nesse relatório, procedeu-se à classificação e à categorização do conteúdo (Figura 2). Por fim, realizou-se o tratamento dos resultados, considerando a inferência e a interpretação desses conteúdos e, consequentemente, a resposta à pergunta norteadora da revisão integrativa ${ }^{8}$. 


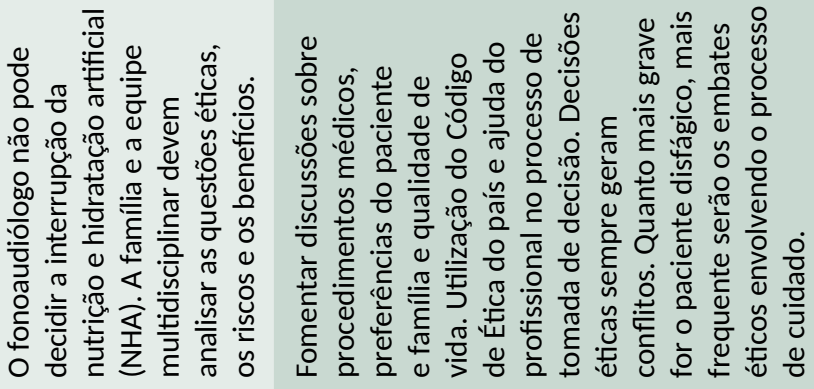

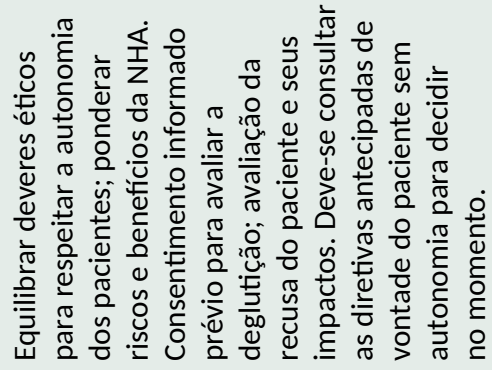
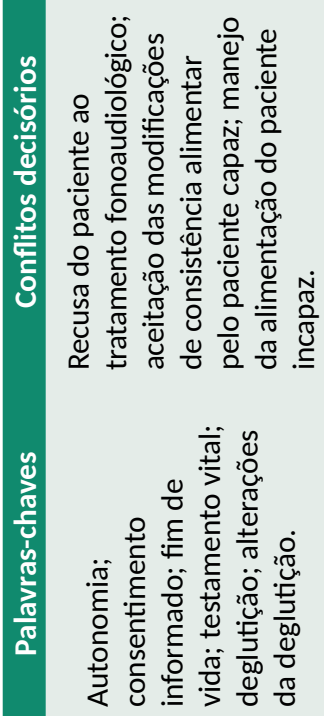

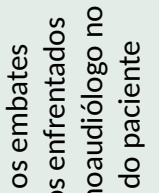

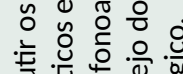
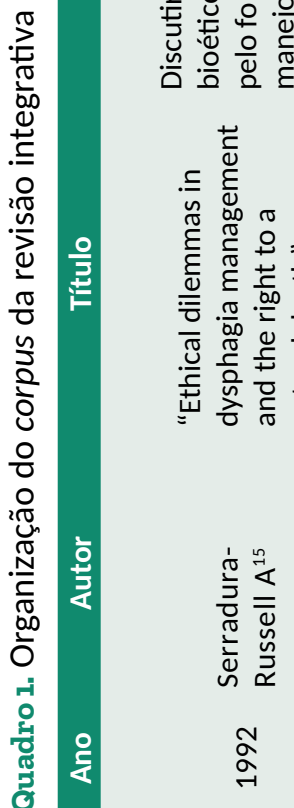
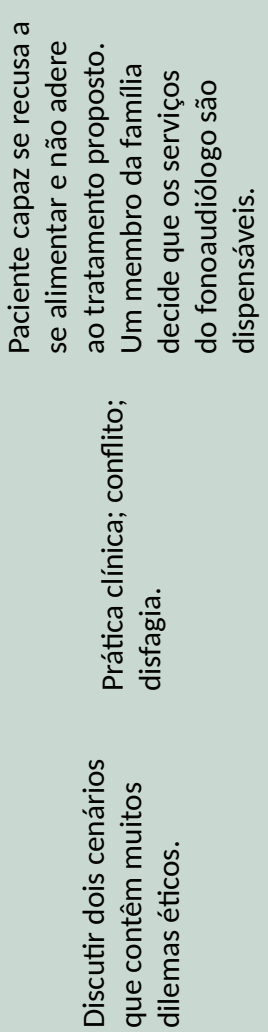

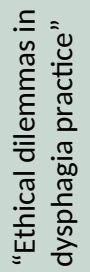

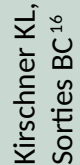

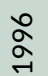

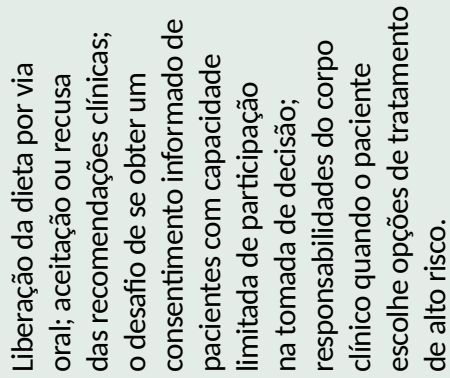

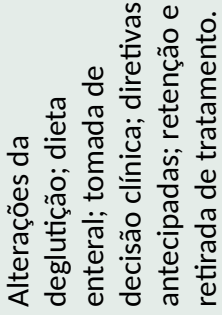
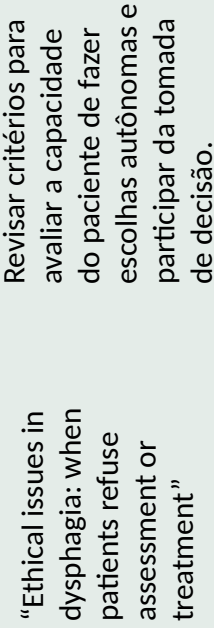

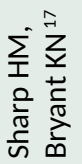

ठ̊ 


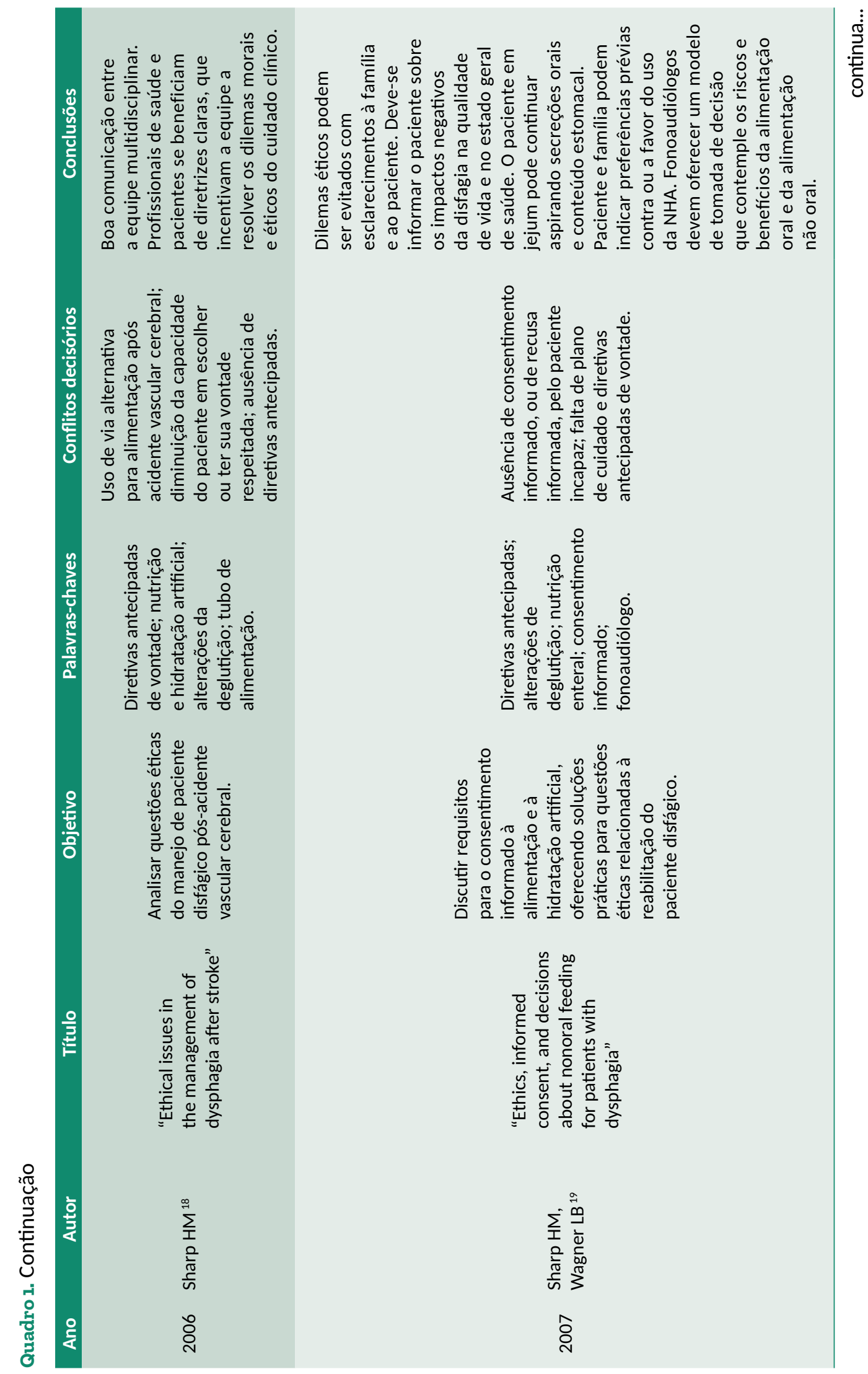




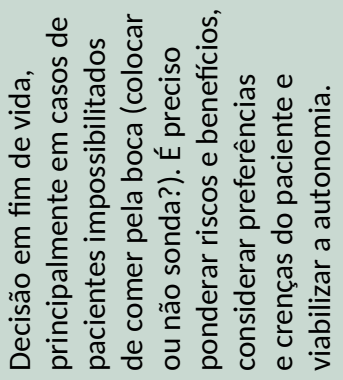

을
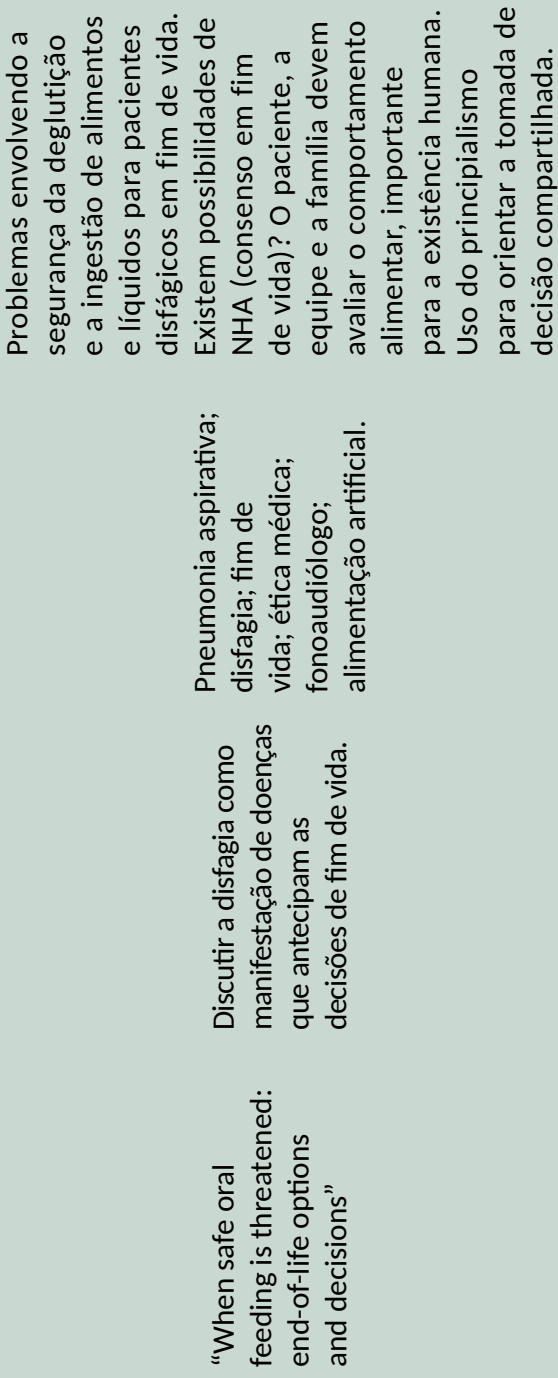

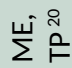

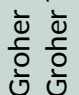

กี
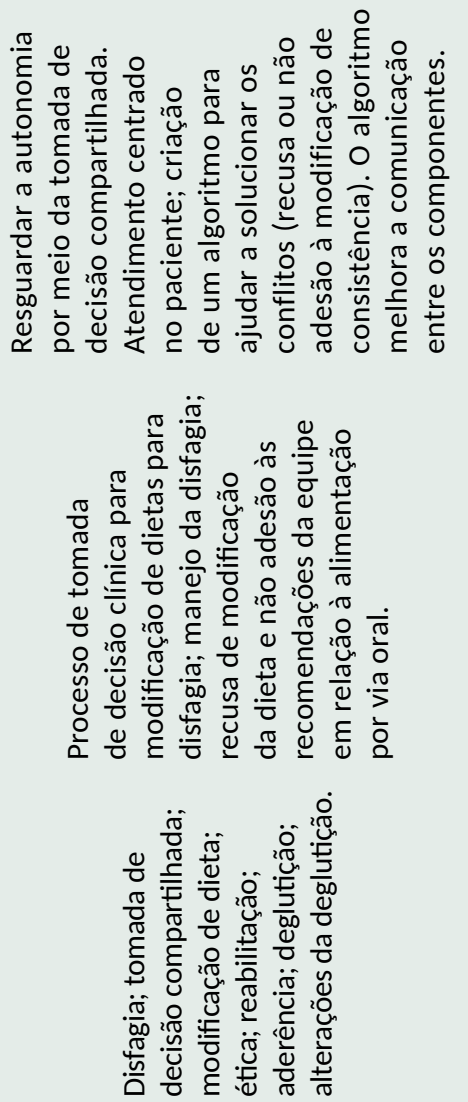

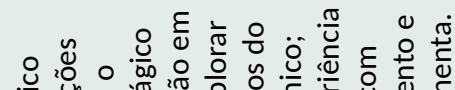

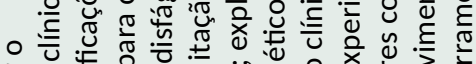

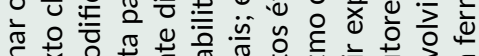

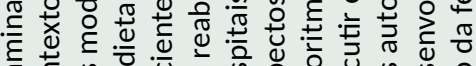

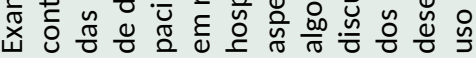
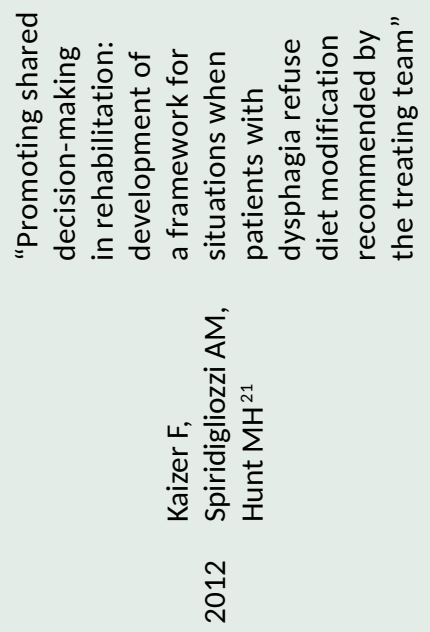

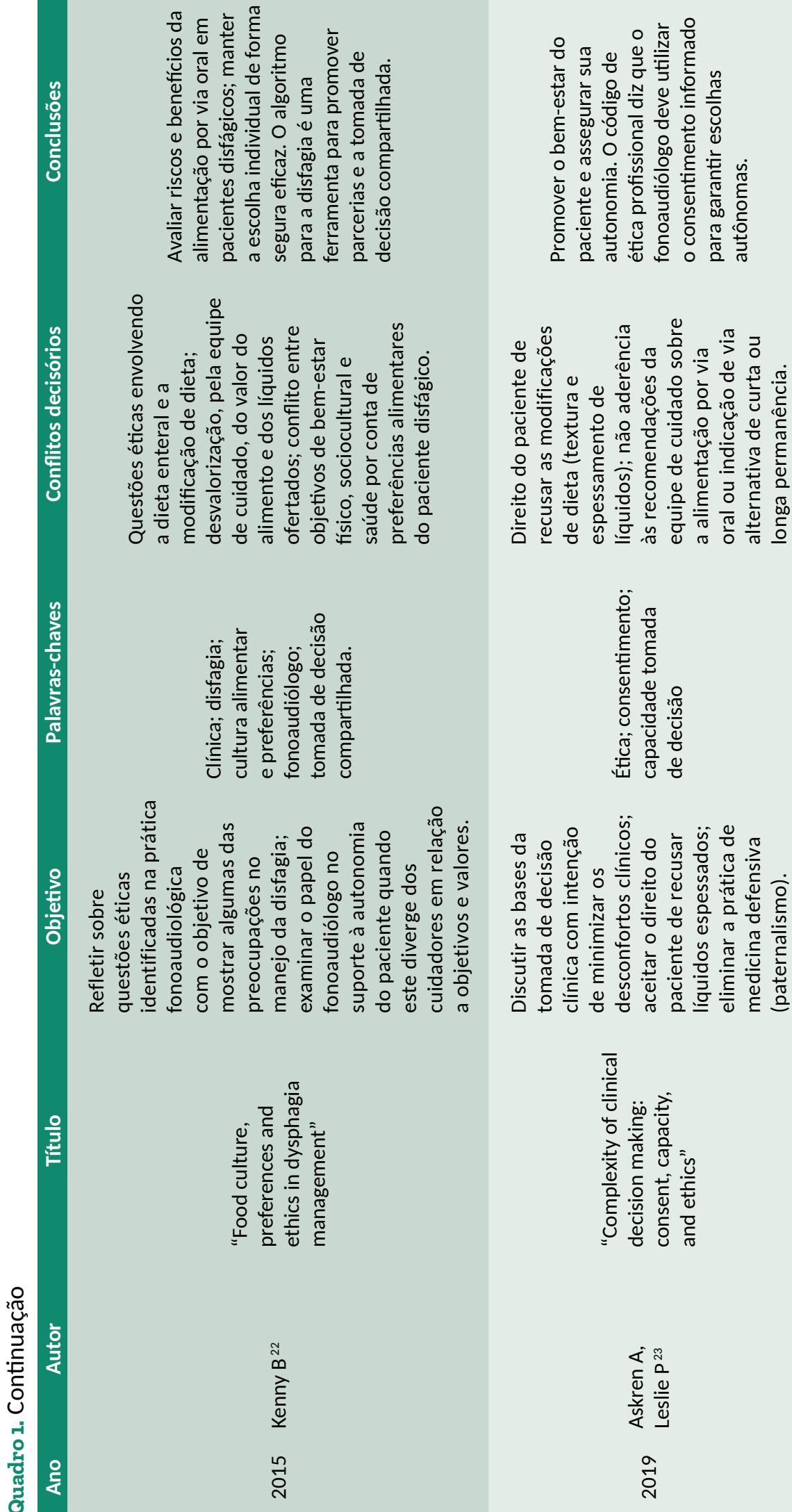
Figura 2. Categorização dos códigos (subcategorias) encontrados no corpus da revisão integrativa

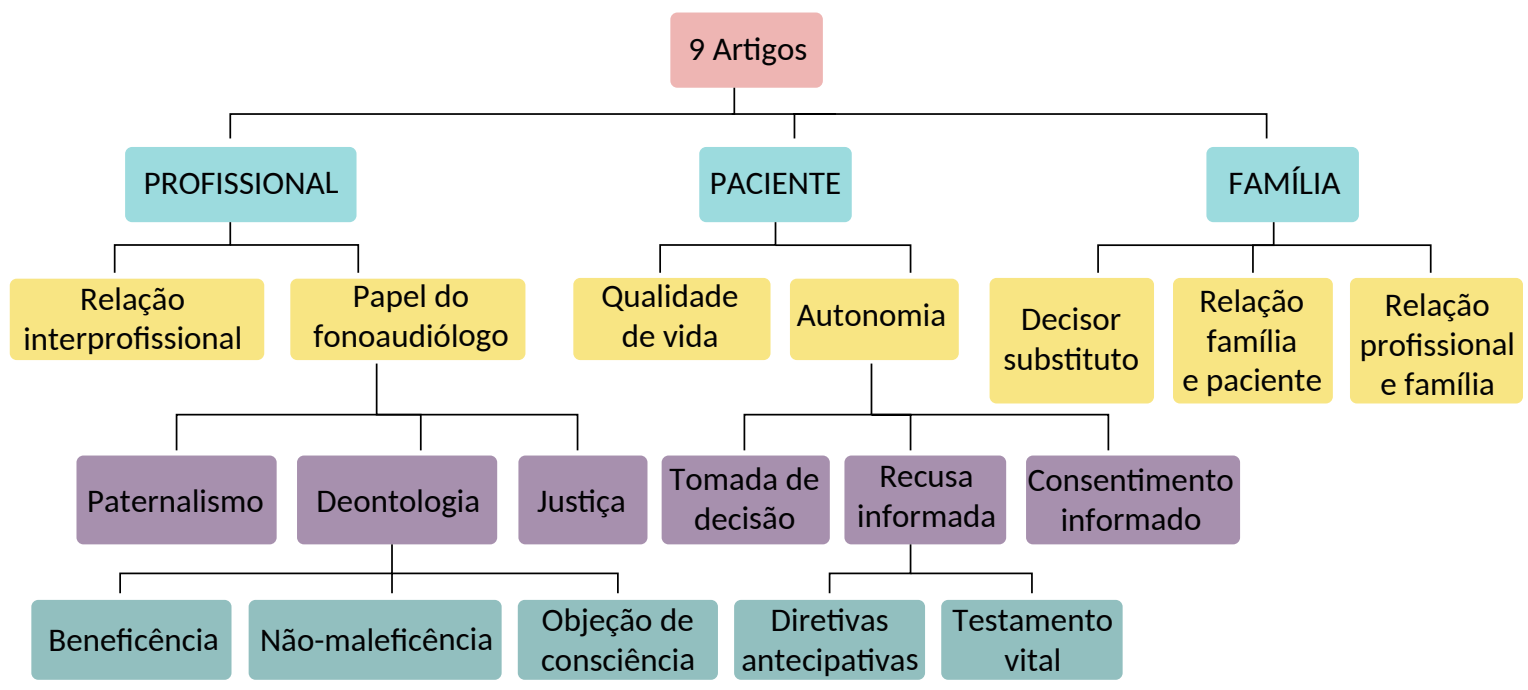

\section{Resultados e discussão}

\section{Bibliometria dos artigos selecionados}

Nove artigos foram selecionados para compor o corpus desta revisão integrativa, todos escritos e publicados em inglês. Como não houve limitação de filtro por tempo, o ano de publicação variou entre 1992 e 2019. O único ano que apresentou mais de uma publicação foi 2012 (dois artigos). O número restrito deve-se à seleção apenas de textos que respondiam à questão norteadora da revisão. Identificaram-se outras publicações relacionadas ao tema, mas que fugiam ao escopo desta pesquisa.

Dos nove artigos, sete são estudos de caso que analisam dilemas e conflitos éticos do ambiente terapêutico ${ }^{15-20,22}$. Outros dois artigos apresentaram modelos e algoritmos para tomada de decisão no cuidado do paciente disfágico ${ }^{21,23}$. Cinco artigos são assinados por pesquisadores dos Estados Unidos ${ }^{16-20}$, o país com mais publicações, seguido da Austrália, com duas publicações ${ }^{22,15}$, e Canadá ${ }^{21}$ e Reino Unido ${ }^{23}$, com uma publicação cada. Cinco periódicos são voltados especificamente à fonoaudiologia. O periódico com maior fator de impacto identificado nesta revisão integrativa é a revista Dysphagia (fator de impacto 3.034), com duas publicações: uma em 1992 (estudo de caso) e outra em 2012 (estudo observacional). Somente um periódico, Bioethics (fator de impacto de 1.665) é específico da área da bioética.

\section{Quais são os agentes envolvidos em conflitos decisórios da prática fonoaudiológica?}

Para a categorização dos artigos - seguindo o método de análise de conteúdo proposto por Bardin -, foram utilizados os relatórios gerados no programa ATLAS.ti. Identificaram-se três principais atores de conflitos decisórios na prática fonoaudiológica (em ordem crescente de ocorrências): 1) família (18\%, 18 ocorrências); 2) paciente $(35 \%, 36)$; e 3) profissionais de saúde $(47 \%, 48)$. Dentro desse escopo, as subcategorias incorporadas na categoria "família" foram "decisor substituto", "relação família e profissional" e "conflitos família e paciente". Já na categoria "paciente", obtiveram-se duas subcategorias principais: "qualidade de vida" e "autonomia" - a esse último se agregaram as subcategorias "tomada de decisão", "recusa informada", "consentimento informado", "diretivas antecipadas de vontade" e "testamento vital". Por fim, na categoria "profissionais de saúde", foram reduzidas para duas subcategorias principais: "relação interprofissional" e "papel do fonoaudiólogo", que englobou as subcategorias "paternalismo", "deontologia", "justiça", "beneficência", "não maleficência" e "objeção de consciência" (Figura 2). 
Conflitos relacionados ao fonoaudiólogo e aos profissionais de saúde

Na categoria "profissional de saúde", foram incluídas oito subcategorias (as porcentagens entre parênteses se referem à ocorrência no corpus): beneficência (19\%), papel do fonoaudiólogo (17\%), justiça (15\%), relação interprofissional (15\%), deontologia (14\%), não maleficência (8\%), paternalismo (8\%) e objeção de consciência (4\%).

As relações interprofissionais devem se basear na discussão dos casos e no compartilhamento de informação, para que não aconteçam mal-entendidos. Quando há diálogo sobre como cada profissional pode contribuir com o manejo e sobre o prognóstico do paciente, conflitos e confusões são evitados. Em se tratando do paciente disfágico sem possibilidade de cura, sempre haverá muitos conflitos decisórios sobre a melhor forma de gerenciar suas demandas ${ }^{15}$. Em suma, as relações entre profissionais e especialidades devem ser pautadas no compartilhamento de informações para não permitir confusões e divergências no tratamento do paciente e manejo de suas necessidades, respeitando as especificidades de cada caso.

$\mathrm{Na}$ verdade, quando ocorrem desacordos no manejo do paciente disfágico - principalmente quando ele recusa avaliação ou tratamento fonoaudiológico especializado -, surge a necessidade de discussão do caso entre médicos, familiares e cuidadores. Sharp e Bryant ${ }^{17}$ também reforçam que a equipe deve sempre se comunicar e compartilhar as deliberações. A informação é importante para decidir qual o melhor caminho para resguardar a autonomia e respeitar as decisões do paciente.

O papel do fonoaudiólogo no manejo da disfagia é muito bem definido, e por isso é essencial que esse profissional entenda os possíveis conflitos decisórios e saiba gerenciar as demandas do paciente. Muitos autores destacam a importância de que a tomada de decisão seja compartilhada entre família, paciente e equipe multidisciplinar. As vontades e desejos do paciente devem ser levadas em consideração para que sua autonomia seja respeitada ${ }^{15-23}$.

Nas questões relativas ao profissional, pode-se perceber a ocorrência de três dos quatro princípios prima facie do principialismo: beneficência (sempre fazer o bem), não maleficência (nunca fazer o mal) e justiça (relacionada com a justiça distributiva e a ponderação entre riscos e benefícios) ${ }^{16,17,20-23}$. O fonoaudiólogo pode utilizar o principialismo para manter o equilíbrio no cuidado em saúde, sempre avaliando as especificidades de cada caso para avaliar qual dos quatro princípios tem mais peso sobre os outros. O profissional, portanto, deve evitar decisões unilaterais, que impedem a participação e desrespeitam a autonomia do paciente. Esse tipo de decisão reforça o paternalismo (quando o médico ou profissional toma decisões sem consentimento e participação ativa dos pacientes) ${ }^{15,17-21}$.

Como assinala Bertachini ${ }^{24}$, a fonoaudiologia gerencia demandas éticas, humanas e técnicas, com foco na prevenção e intervenção nas áreas da saúde, educação e pesquisa. O fonoaudiólogo está habilitado a intervir no enfrentamento de questões relacionadas à comunicação humana que prejudicam a interação social, o convívio familiar, o aprendizado e a gestão de pessoas. Um dos mecanismos para evitar esses impactos negativos é a escuta empática, que por sua vez permite a comunicação assertiva, possibilitando ao paciente ser protagonista na tomada de decisão, expressando seus sentimentos e vontades ${ }^{24}$.

Bertachini ${ }^{24}$ ainda aponta que a fonoaudiologia e a bioética compartilham os mesmos propósitos e princípios: confidencialidade, privacidade, alteridade, prudência, vulnerabilidade, acolhimento, respeito à vida e qualidade de vida. Desse modo, a bioética é uma ferramenta que ajuda o fonoaudiólogo a lidar com conflitos decisórios.

Outra situação que pode levar a conflitos diz respeito à objeção de consciência. O profissional de saúde pode se recusar a realizar algum procedimento em respeito a crenças e valores pessoais. O conceito de moralidade e do que é ético é bem delimitado, mas o entendimento pode divergir de pessoa para pessoa - o que gera conflitos na tomada de decisão ${ }^{17,19}$. Nesses casos, o direito à autonomia do paciente sofre interferências e acaba sendo desrespeitado.

Como documentos deontológicos, os códigos de ética profissional versam sobre questões éticas relacionadas ao cuidado e a interações que envolvem terapeuta e paciente, prestador de serviço e cliente. A deontologia, em suma, visa à regulação ética das relações interprofissionais e interpessoais ${ }^{16-23}$. Desse modo, o Código de Ética da Fonoaudiologia ${ }^{25}$, baseado nos princípios da 
Declaração Universal sobre Bioética e Direitos Humanos ${ }^{26}$, também fornece ao fonoaudiólogo um embasamento teórico que pode ser utilizado na resolução de conflitos decisórios.

\section{Conflitos relacionados ao fonoaudiólogo e aos pacientes}

Na categoria "pacientes", foram incluídas sete subcategorias (as porcentagens entre parênteses se referem à ocorrência no corpus): autonomia (25\%), diretivas antecipadas (25\%), recusa informada (14\%), testamento vital (14\%), qualidade de vida (8\%), tomada de decisão compartilhada (8\%) e consentimento informado (6\%).

O conceito de qualidade de vida determina o bem-estar do paciente disfágico, sua condição de manter a dignidade humana e a autonomia. O paciente pode gerir suas vontades de acordo com o próprio entendimento do que seja qualidade de vida e como esta impacta no seu dia a dia. O conceito também se relaciona com a funcionalidade, muito valorizada em situações limitadoras, quando o paciente é acometido por doença incurável e progressiva. Resumindo, a qualidade de vida é um parâmetro para definir condutas no manejo de pacientes disfágicos ${ }^{16,20-22}$.

Outro princípio relacionado com a categoria "paciente" e advindo do principialismo de Beauchamp e Childress ${ }^{27}$ é o respeito à autonomia. Um paciente autônomo é capaz de realizar suas escolhas e expressar seus próprios desejos por meio do consentimento informado, decidindo sobre seu bem-estar, situação de saúde e processo de cuidado ${ }^{15-21,23}$. O paciente também pode recusar procedimentos que julgue extraordinários ou que possam causar mais sofrimento. Essa recusa, tal como o consentimento, deve ser informada ${ }^{15-23}$.

A autonomia do paciente se relaciona com a tomada de decisão compartilhada. Nesse processo, para se chegar a uma escolha que atenda às necessidades do paciente, a deliberação deve se basear na colaboração e na divisão de responsabilidades ${ }^{15-23}$. O artigo $5^{\circ}$ da Declaração Universal sobre Bioética e Direitos Humanos ${ }^{26}$ deixa claro o dever de respeitar a autonomia da pessoa, preconizando a independência do indivíduo em decidir o que deseja para a própria vida. A tomada de decisão compartilhada visa resguardar esses direitos. O fonoaudiólogo pode ajudar nesse processo, respeitando tanto a recusa quanto o consentimento do paciente.

No que se refere à autonomia, o paciente pode se beneficiar das diretivas antecipadas de vontade (DAV), cujo principal objetivo é garantir que suas decisões sobre passar ou não por determinados procedimentos sejam respeitadas. O Conselho Federal de Medicina (CFM) ${ }^{28}$ define as DAV como um conjunto de desejos, prévia e expressamente manifestados pelo paciente, sobre cuidados e tratamentos que quer, ou não, receber no momento em que estiver incapacitado de expressar, livre e autonomamente, sua vontade. Esse conjunto de desejos do paciente ou de seu representante legal deve estar em acordo com o Código de Ética Médica havendo desacordo, o médico poderá ignorá-lo.

As DAV prevalecem sobre qualquer outro parecer que não seja dado pelo médico, incluindo a opinião da família. As diretivas antecipadas devem ser registradas em prontuário, e o registro em cartório é facultativo, tendo em vista que por ora a execução por parte dos médicos não é assegurada pela legislação. Ressalta-se, ainda, que há decisões judiciais que impedem determinados procedimentos, mesmo com vontade expressa do paciente. No caso de ausência de DAV, o médico pode consultar o comitê de bioética clínica do hospital, a comissão de ética médica ou o próprio CFM para balizar suas decisões ${ }^{28}$. Por fim, vale lembrar que o paciente que registrou diretivas pode mudar suas decisões em qualquer momento ${ }^{17-20}$. Dessa forma, fica assegurado o direito do paciente de expressar previamente seus desejos, antecipando-se a possíveis situações de incapacidade de decidir por si só.

Há duas modalidades de DAV: testamento vital e mandato duradouro. No testamento vital, o paciente registra desacordos e concordâncias em relação a determinados procedimentos médicos. Nesse caso, o doente exerce a pura autonomia, como preconizada por Beauchamp e Childress ${ }^{27}$, pois participa ativa e conscientemente da tomada de decisão sobre seus cuidados. Já o mandato duradouro é um modelo de julgamento substitutivo, por meio do qual o paciente nomeia um procurador para decidir por ele em caso de incapacidade. Esses dois modelos podem estar juntos ou em documentos distintos, mas ambos têm o objetivo de garantir o respeito à autonomia. Quando o paciente explicita nesses documentos o que 
deseja, torna-se mais fácil gerenciar os conflitos da tomada de decisão ${ }^{29}$.

No testamento vital, o paciente pode deixar registrada a recusa ou desejo de suspender medidas extraordinárias que prolonguem sua vida e aumentem seu sofrimento. Essas medidas podem incluir: nutrição e hidratação artificial (NHA), ventilação mecânica e ressuscitação, principalmente em cuidados paliativos ou fim de vida ${ }^{17-19}$. Muito discutida na literatura por causa de controvérsias sobre seus benefícios, a NHA pode acarretar implicações jurídicas para o profissional de saúde ${ }^{17-19}$. Por isso, mesmo embasados pela literatura médica ou, ainda, com aval do paciente ou decisor substituto ${ }^{29}$, médicos tendem a ser cautelosos ao suspender a NHA.

\section{Conflitos relacionados ao fonoaudiólogo e à família}

$\mathrm{Na}$ categoria família, foram incluídas três subcategorias (as porcentagens entre parênteses se referem à ocorrência no corpus): "conflito família e paciente" (22\%), "relação profissional e família" (39\%) e "decisor substituto" (39\%). Na relação entre família e paciente, é muito comum que surjam desacordos. Por diferentes motivos, frequentemente a família tende a tomar decisões sem incluir o paciente. Essa postura pode se dever, por exemplo, a uma tentativa de poupar o doente de conhecer sua real condição de saúde, ou ainda a divergências sobre escolhas do paciente. Sem conhecimento do diagnóstico médico ou das possibilidades terapêuticas existentes, a autonomia do paciente fica comprometida ${ }^{16-19,22}$. Dessa forma, reforça-se que o doente tem direito a tomar decisões e ser respeitado integralmente enquanto ser humano.

Na relação entre profissional e família, as discordâncias podem ser resolvidas quando o profissional apresenta todas as possibilidades de tratamento e intervenções, permitindo a tomada de decisão compartilhada. As demandas da família fornecem informações detalhadas sobre como o paciente vivia, seus hábitos e preferências, e portanto devem ser levadas em conta. Cabe ao fonoaudiólogo ser sensível às angústias dos familiares em relação ao cuidado do paciente e registrar as decisões tomadas nas reuniões com a família ${ }^{15-18,20-22}$.

O paciente pode definir um membro da família ou pessoa próxima para ser o decisor substituto em caso de incapacidade de se autogerir e decidir por si mesmo. As questões sobre suspensão ou recusa de procedimentos relacionados à alimentação podem ser deliberadas pelo decisor substituto $^{29}$, que deverá legislar em favor da pessoa que o instituiu, sem confundir seus desejos, crenças e vontades com os do paciente ${ }^{15-20,23}$.

\section{Considerações finais}

Respondendo à pergunta norteadora dessa revisão integrativa ("Quais são os principais atores da tomada de decisão envolvendo paciente disfágico e quais são os conflitos enfrentados por eles?"), identificou-se que cabe ao fonoaudiólogo gerenciar os conflitos decisórios, que envolvem principalmente três atores: paciente, profissional e família. A revisão ainda identificou possíveis conflitos (subcategorias) relacionados a cada um desses atores. Tais conflitos envolvem com mais frequência o profissional e, logo em seguida, o paciente.

Conclui-se que são necessárias mudanças atitudinais da equipe multidisciplinar e dos cuidadores em relação ao paciente disfágico. As deliberações devem envolver a todos para que a tomada de decisão seja mais assertiva e resguarde a autonomia do paciente, tratando-o como protagonista de suas ações e escolhas.

As demandas familiares também devem receber atenção, pois a angústia da família e a falta de informações podem interferir no cuidado ao doente, principalmente em questões relacionadas à alimentação. Ficou claro que a suspensão da NHA ou a liberação da dieta de conforto para paciente em fim de vida podem gerar desacordos entre profissional de saúde, família e o próprio paciente. Para evitar conflitos, a deliberação deve ser compartilhada.

Observou-se que não há uma teoria ou modelo que o fonoaudiólogo possa utilizar para resolver conflitos éticos envolvendo a alimentação do paciente disfágico. Idealmente, as decisões clínicas do profissional se baseiam em boas práticas e em evidências científicas, mas ainda há poucos estudos sobre o tema. Sugere-se, portanto, que o Código de Ética da Fonoaudiologia e o referencial teórico da bioética sejam usados como suporte para a resolução de conflitos decisórios. 


\section{Referências}

1. Rego S, Palacios M, Siqueira-Batista R. A bioética e suas teorias. In: Rego S, Palacios M, Siqueira Batista R. Bioética para profissionais de saúde. Rio de Janeiro: Editora Fiocruz; 2014. p. 39-62.

2. Pessini L, Barchifontaine P. Problemas atuais de bioética. 11ª ed. São Paulo: Loyola; 2014.

3. Brasil. Lei $n^{\circ}$ 6.965, de 9 de dezembro de 1981. Dispõe sobre a regulamentação da profissão de Fonoaudiólogo, e determina outras providências. Diário Oficial da União [Internet]. Brasília, 10 dez 1981 [acesso 3 mar 2021]. Disponível: https://bit.ly/3e2u6QT

4. Brasil. Decreto $n^{\circ} 87.218,31$ de maio de 1982. Regulamenta a Lei $n^{\circ} 6.965$, de 09 de dezembro de 1981, que dispõe sobre a regulamentação da profissão de Fonoaudiólogo, e determina outras providências. Diário Oficial da União [Internet]. Brasília, 1982 [acesso 3 mar 2021]. Disponível: https://bit.ly/2PwM6Js

5. Conselho Federal de Fonoaudiologia. Resolução $n^{\circ} 492,7$ de abril de 2016. Dispõe sobre a regulamentação da atuação do profissional fonoaudiólogo em disfagia e dá outras providências. Diário Oficial da União [Internet]. Brasília, 18 abr 2016 [acesso 3 mar 2021]. Disponível: https://bit.ly/3vzQgQp

6. Costa M. Disfagia oral e/ou faríngea e distúrbios referentes. In: Costa M. Deglutição e disfagia: bases morfofuncionais e videofluoroscópicas. Rio de Janeiro: Medbook; 2013. p. 179-95.

7. Jotz GP, Dornelles S. Fisiologia da deglutição. In: Jotz GP, Carrara-de-Angelis E, Barros, APB. Tratado de deglutição e disfagia: no adulto e na criança. Rio de Janeiro: Revinter; 2009. p. 16-9.

8. Bardin L. Análise de conteúdo. Lisboa: Edições 70; 2016.

9. Whittemore R, Knafl K. The integrative review: updated methodology. J Adv Nurs [Internet]. 2005 [acesso 3 mar 2021];55(5):546-53. DOI: 10.1111/j.1365-2648.2005.03621.x

10. Cullum N, Ciliska D, Haynes RB, Marks S. Enfermagem baseada em evidências: uma introdução. Porto Alegre: Artmed; 2010.

11. Joanna Briggs Institute. Joanna Briggs Institute Reviewers' Manual. Adelaide: Joanna Briggs Institute; 2008.

12. Souza MT, Silva MD, Carvalho R. Revisão integrativa: o que é e como fazer? Einstein [Internet]. 2010 [acesso 3 mar 2021];8(1):102-6. DOI: 10.1590/s1679-45082010rw1134

13. Moher D, Liberati A, Tetzlaff J, Altman DG, The PRISMA Group. Preferred reporting items for systematic reviews and meta-analyses: the PRISMA statement. PLoS Med [Internet]. 2009 [acesso 29 abr 2021];6(7). DOI: 10.1371/journal.pmed.1000097

14. Lockwood C, Munn Z, Porritt K. Qualitative research synthesis: methodological guidance for systematic reviewers utilizing meta-aggregation. Int J Evid Based Healthc [Internet]. 2015;13(3):179-87. DOI: 10.1097/ XEB. 0000000000000062

15. Serradura-Russell A. Ethical dilemmas in dysphagia management and the right to a natural death. Dysphagia [Internet]. 1992 [acesso 3 mar 2021];7(2):102-5. DOI: 10.1007/BF02493440

16. Kirschner KL, Sorties BC. Ethical dilemmas in dysphagia practice. Top Stroke Rehabil [Internet]. 1996 [acesso 3 mar 2021];3(3):87-93. DOI: 10.1080/10749357.1996.11754124

17. Sharp HM, Bryant KN. Ethical issues in dysphagia: when patients refuse assessment or treatment. Semin Speech Lang [Internet]. 2003 [acesso 3 mar 2021];24(4):285-99. DOI: 10.1055/s-2004-815578

18. Sharp HM. Ethical issues in the management of dysphagia after stroke. Top Stroke Rehabil [Internet] 2006 [acesso 3 mar 2021];13(4):18-25. DOI: 10.1310/tsr1304-18

19. Sharp HM, Wagner LB. Ethics, informed consent, and decisions about nonoral feeding for patients with dysphagia. Top Geriatr Rehabil [Internet]. 2007 [acesso 3 mar 2021];23(3):240-8. DOI: 10.1097/ 01.TGR.0000284768.32334.96

20. Groher ME, Groher TP. When safe oral feeding is threatened: end-of-life options and decisions. Top Lang Disord [Internet]. 2012 [acesso 3 mar 2021];32(2):149-67. DOI: 10.1097/TLD.0b013e3182543547

21. Kaizer F, Spiridigliozzi AM, Hunt MH. Promoting shared decision-making in rehabilitation: development of a framework for situations when patients with dysphagia refuse diet modification recommended by the treating team. Dysphagia [Internet]. 2012 [acesso 3 mar 2021];27(1):81-7. DOI: 10.1007/s00455-011-9341-5 
22. Kenny B. Food culture, preferences and ethics in dysphagia management. Bioethics [Internet]. 2015 [acesso 3 mar 2021];29(9):646-52. DOI: 10.1111/bioe.12189

23. Askren A, Leslie P. Complexity of clinical decision making: consent, capacity, and ethics. Semin Speech Lang [Internet]. 2019 [acesso 3 mar 2021];40(3):162-9. DOI: 10.1055/s-0039-1688838

24. Bertachini L. Fonoaudiologia e bioética: reflexões (bio)éticas na prática profissional. In: Sganzerla A, Chemim MRC, Rauli PMF, editores. Bioética nas profissões: ciências da saúde e áreas afins. Curitiba: CRV; 2019. p. 79-98.

25. Conselho Federal de Fonoaudiologia. Código de Ética da Fonoaudiologia [Internet]. Brasília: Conselho Federal de Fonoaudiologia; 2016 [acesso 10 jan 2020]. Disponível: https://bit.ly/3gClLF5

26. Organização das Nações Unidas para a Educação, Ciência e Cultura. Declaração Universal sobre Bioética e Direitos Humanos [Internet]. Paris: Unesco; 2005 [acesso 27 mar 2021]. Disponível: https://bit.ly/3u5C2pR

27. Beauchamp TL, Childress JF. Respect for autonomy. In: Beauchamp TL, Childress JF. Principles of biomedical ethics. $8^{\text {a }}$ ed. New York: Oxford University Press; 2019. p. 99-159.

28. Conselho Federal de Medicina. Resolução CFM n 1.995/2012. Dispõe sobre as diretivas antecipadas de vontade e dá outras providências. Diário Oficial da União [Internet]. Brasília, p. 269-70, 31 ago 2012 [acesso 27 mar 2021]. Seção 1. Disponível: https://bit.ly/2RdnS7q

29. Dadalto L, Tupinambás U, Greco DB. Diretivas antecipadas de vontade: um modelo brasileiro. Rev. bioét. (Impr.). [Internet]. 2013 [acesso 28 mar 2021];21(3):463-76. DOI: 10.1590/S1983-80422013000300011

Márcio José da Silva Moreira - Doutor - marciomoreira@id.uff.br

(iD) 0000-0003-0072-9507

Roberta Nascimento de Oliveira Lemos dos Santos - Doutora - roberta_o_lemos@hotmail.com

(D) 0000-0001-9658-1185

Marisa Palacios - Doutora - marisa.palacios@gmail.com

(D) 0000-0001-6507-4199

Correspondência

Marcio José da Silva Moreira - Rua Noronha Torrezão, 407, bloco 12, apt. 601 CEP 24240-181. Niterói/RJ, Brasil.

Participação dos autores

Márcio José da Silva Moreira e Roberta Nascimento de Oliveira Lemos dos Santos contribuíram igualmente para a elaboração do artigo. Marisa Palacios orientou o projeto e realizou a revisão 